\title{
Evening indomethacin in the treatment of rheumatoid arthritis
}

\author{
E. C. HUSKISSON, R. T. TAYLOR, D. BUR S T O N, P. J . CHUTER, A D \\ F. DUDLEY HART
}

Westminster Hospital, London

\begin{abstract}
A large dose of indomethacin, given at night, has been found to be effective in relieving the morning pain and stiffness which are such prominent features of active rheumatoid arthritis. Suppositories containing $100 \mathrm{mg}$. of the drug have usually been used, but are not popular in Great Britain. Patients with hand deformities find it difficult to insert them without help, and rectal irritation may be a problem, especially with prolonged use. Preliminary observations in a few patients suggested that the same dose of oral indomethacin given at night was even more effective. We therefore undertook a formal trial to compare the effectiveness and acceptability of $100 \mathrm{mg}$. indomethacin given orally with $100 \mathrm{mg}$. given by suppository.
\end{abstract}

\section{Methods}

\section{(1) DESIGN OF TRIAL}

Twenty patients in hospital with rheumatoid arthritis were admitted to the trial. Nineteen had classical or definite rheumatoid arthritis by the criteria of the American Rheumatism Association (Ropes, Bennett, Cobb, Jacox, and Jessar, 1959); they tended to have active disease in relapse. One patient was thought to have rheumatoid arthritis but subsequently proved to have primary amyloidosis. The trial was double-blind and a balanced crossover design was used. There was an initial control period lasting a few days to ensure stability. The trial period then lasted for 4 consecutive days. One group of ten patients received daily treatment in the following order:

A Indomethacin suppository and four placebo capsules

B Placebo suppository and four indomethacin capsules

C Indomethacin suppository and four placebo capsules

D Placebo suppository and four indomethacin capsules

The other group received the same treatments in the order B, A, D, C. Patients were allocated randomly to one or other treatment order. Treatment was given at 9 p.m.

Assessments were made at 9 a.m. on the morning after administration of each treatment. The patients kept a record of morning pain and stiffness expressed as a percentage based on 100 per cent. for the control period. Smaller figures represent improvement and larger figures represent deterioration. Duration of morning stiffness was also noted. Measurements of interphalangeal joint swelling (Boardman and Hart, 1967a), grip strength, and assessments of tenderness of hand joints were made by two observers (R.T.T. and E.C.H.) in thirteen of the patients. The same observer made all the measurements in any one patient. Preference was recorded for each pair of nights and any side-effects were noted.

\section{(2) SERUM INDOMETHACIN LEVELS}

Estimations were made of serum indomethacin in seven patients 1, 2, 3, and 12 hours after administration of each treatment. All reagents and the stock solution of indomethacin were prepared according to the methods of Holt and Hawkins (1965).

Working standards were prepared by adding volumes of the stock indomethacin solution $(25 \mu \mathrm{g} . / \mathrm{ml}$.) to three batches of a serum pool to give indomethacin concentrations of $0,2 \cdot 5$, and $5 \mu \mathrm{g}$. $/ \mathrm{ml}$. The three batches of sera were then divided into aliquots of $1.5 \mathrm{ml}$. and stored at $-20^{\circ} \mathrm{C}$.

The method used for estimating indomethacin in serum was based on that described by Holt and Hawkins (1965) in which the indomethacin was extracted from citrate buffered serum with $\mathrm{N}$-heptane. After a further wash with citrate buffer, the heptane was shaken with $0 \cdot 1 \mathrm{M} \mathrm{NaOH}$, the phases separated by centrifugation, and the lower aqueous phase removed for fluorescence intensity measurement: Occasionally turbidity developed in the aqueous phase at this stage necessitating a further centrifugation. The fluorescence intensity of the clear aqueous phase was measured in a Hitachi, Perkin-Elmer MPF 2A recording spectrofluorimeter. The excitation wavelength was $295 \mathrm{~m} \mu$., and emission was measured at $370 \mathrm{~m} \mu$.

With each batch of determinations a serum blank, two standards $(2.5$ and $5 \mu \mathrm{g}$. $/ \mathrm{ml}$.) and as a quality control a serum from a previously measured batch was run. Repeat analysis of a serum usually gave values within $0 \cdot 2 \mu \mathrm{g}$. of each other, and repeat analysis of a serum after one month at $-20^{\circ} \mathrm{C}$. showed no drop in the indomethacin level. 


\section{Results}

\section{(1) PREFERENCE}

Patients' preferences are shown in Table I. Two crossovers were performed in each patient, the first on the first and second nights of the trial, and the second on the third and fourth nights. The preferences in each crossover are shown separately and consistent preferences are shown below. Sixteen of the twenty patients were consistent, preferring the same treatment, or neither, in both crossovers.

Analysis of the consistent preferences shows that oral therapy was favoured and the difference was statistically significant $(P<0.05$, using the McNemar test).

Table I Preference

\begin{tabular}{|c|c|c|c|c|}
\hline \multirow[t]{2}{*}{ Result } & \multicolumn{2}{|c|}{ Preference } & \multirow{2}{*}{$\begin{array}{l}\text { No } \\
\text { preference }\end{array}$} & \multirow[t]{2}{*}{ Total } \\
\hline & Capsules & Suppository & & \\
\hline $\begin{array}{l}\text { First } \\
\text { Crossover } \\
\text { Second }\end{array}$ & 11 & 3 & 6 & 20 \\
\hline Crossover & 11 & 1 & 8 & 20 \\
\hline Consistent & 9 & 1 & 6 & 16 \\
\hline
\end{tabular}

\section{(2) SUBJECTIVE ASSESSMENTS}

The means of patients' assessments are shown in Table II. While the comparison of capsules and suppositories was double blind, the comparison of control and treatment was not. The figures, however, suggest that though capsules are more effective, the difference between the two treatments is less than the effectiveness of either.

Table II Subjective assessments

\begin{tabular}{|c|c|c|c|}
\hline \multirow[t]{3}{*}{ Series } & Pain & Stiffness & Duration of \\
\hline & (per cent.) & (per cent.) & stiffness \\
\hline & & & $(\min )$. \\
\hline Control & 100 & 100 & 227 \\
\hline $\begin{array}{l}\text { Capsules } \\
\text { Suppository }\end{array}$ & $\begin{array}{l}79 \\
85\end{array}$ & $\begin{array}{l}83 \\
82\end{array}$ & $\begin{array}{l}161 \\
192\end{array}$ \\
\hline
\end{tabular}

The figures for pain and stiffness are not comparable from patient to patient, since one patient might regard a moderate improvement as $\mathbf{5 0}$ per cent., another as 5 per cent. Only the direction of the change can therefore be taken as significant. The differences between the means of the capsule and suppository days in each patient were analysed according to the direction of the change, if any, using the sign test. This showed that pain relief was more often obtained with capsules than with suppositories and the difference was statistically significant $(P<0.02)$. Greater relief of stiffness was also more often obtained with capsules but the difference was not significant $(P \bumpeq 0.06)$.

The mean duration of morning stiffness on the two treatments was analysed by the Wilcoxon matchedpairs signed-ranks test and the differences were not statistically significant $(P>0 \cdot 1)$. The mean is misleading and reflects a dramatic improvement in one patient.

\section{(3) OBJECTIVE ASSESSMENTS}

Mean changes in joint size, grip strength, and tenderness are shown in Table III. Again, the improvement is more marked with capsules.

Table III Objective criteria

\begin{tabular}{|c|c|c|c|}
\hline Series & $\begin{array}{l}\text { Change in } \\
\text { joint size } \\
\text { (mm.) }\end{array}$ & $\begin{array}{l}\text { Grip strength } \\
(\mathrm{mm} . \mathrm{Hg})\end{array}$ & $\begin{array}{l}\text { Tenderness } \\
\text { (units) }\end{array}$ \\
\hline Control & 0 & 200 & $15 \cdot 2$ \\
\hline $\begin{array}{l}\text { Capsules } \\
\text { Suppository }\end{array}$ & $\begin{array}{l}+3 \cdot 8 \\
+1\end{array}$ & $\begin{array}{l}211 \\
204\end{array}$ & $\begin{array}{l}12 \cdot 5 \\
13 \cdot 2\end{array}$ \\
\hline
\end{tabular}

The direction and size of the differences in these parameters on the two treatments was calculated for each patient. More patients showed a reduction in joint size on capsules and using the ' $t$ ' test applied to these paired data, the differences were found to be statistically significant $(P<0.02)$. The differences in grip strength and joint tenderness were not significant.

\section{(4) PERIOD EFFECTS}

The preferences for each period of each crossover were analysed by the method suggested by Mainland (1963), which showed that there was no significant period effect.

The means of all the recordings for each day of the trial, regardless of treatment, are shown in Table IV.

Table IV Mean recordings for each day of the trial

\begin{tabular}{|c|c|c|c|c|c|}
\hline Symptom & Contro & l Day 1 & Day 2 & Day 3 & Day 4 \\
\hline $\begin{array}{l}\text { Pain } \\
\text { Stiffness }\end{array}$ & $\begin{array}{l}100 \\
100\end{array}$ & $\begin{array}{l}79 \\
87\end{array}$ & $\begin{array}{l}77 \\
83\end{array}$ & $\begin{array}{l}87 \\
81\end{array}$ & $\begin{array}{l}85 \\
82\end{array}$ \\
\hline $\begin{array}{l}\text { Limbering-up } \\
\text { time } \\
\text { Joint size } \\
\text { Grip strength } \\
\text { Tenderness }\end{array}$ & $\begin{array}{c}227 \\
0 \\
200 \\
15 \cdot 2\end{array}$ & $\begin{array}{c}137 \\
+3 \\
206 \\
14 \cdot 6\end{array}$ & $\begin{array}{c}191 \\
+1.5 \\
209 \\
12.6\end{array}$ & $\begin{array}{c}186 \\
+1 \cdot 2 \\
204 \\
12 \cdot 5\end{array}$ & $\begin{array}{c}191 \\
+3 \cdot 9 \\
213 \\
11 \cdot 7\end{array}$ \\
\hline
\end{tabular}


Except in terms of grip strength and tenderness, the most marked changes occurred on the first day and there was little, if any, tendency to subsequent improvement. Grip strength and tenderness tend to improve slowly. We were surprised that significant effects in the other parameters could be recorded 12 hours after administration of a drug; it is clear that indomethacin is very quick acting, and if its effect is not apparent on the morning after the administration of $100 \mathrm{mg}$. it is unlikely to be effective at all.

\section{(5) SIDE-EFFECTS}

Nausea, anorexia, or epigastric discomfort were noted on four out of eighty trial nights, twice after capsules and twice after suppositories. There were no other side-effects during the trial and no complaints of headaches or muzziness.

Seventeen of the twenty patients continued to take four indomethacin capsules nightly, often with the addition of three during the day. Two continued on suppositories, one for preference and one because they were more effective in the trial; one of these patients has since stopped indomethacin because of indigestion. One patient did not continue treatment because it was completely without effect. Of the seventeen patients continuing on capsules, indigestion has occurred in five. In two it was necessary to stop treatment but in three it was possible to reduce the dose with little loss of effect and with relief of indigestion. In one patient treatment was stopped because of purpura which was unrelated. Eleven patients were still taking the full dose after 10 to 14 months of follow-up.

\section{(6) SERUM INDOMETHACIN LEVELS}

Mean serum indomethacin levels are shown in the Figure.

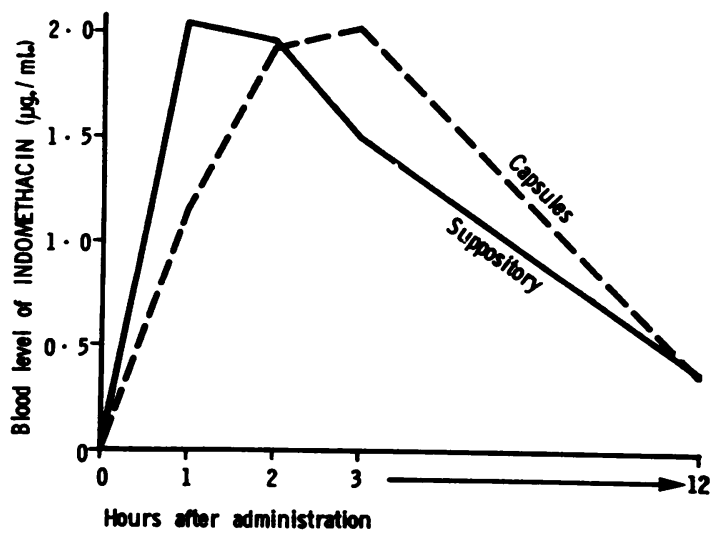

FIGURE Mean serum indomethacin levels after administration of capsules and suppositories up to 12 hrs after dosage.

\section{Discussion}

The greater effectiveness of orally administered indomethacin demonstrated in this double-blind trial is surprising and unexplained. Though capsules are more slowly absorbed, blood levels measured 12 hours after administration, when clinical assessments were made, did not differ. Tissue levels may be more important. The blood levels obtained in our cases were similar to those of Holt and Hawkins (1965), though we did not confirm their finding of higher peak levels nor the greater variability following capsules.

Most authors have found suppositories effective, though few have compared the two routes. Woolf (1965) found suppositories more effective than capsules in seven patients, capsules more effective in four, and no difference in ten. The dosage of capsules used is not clearly stated and the majority of his patients suffered from disorders other than rheumatoid arthritis in which the morning pain and stiffness may be less prominent.

Suppositories have been used to avoid the gastric side effects of indomethacin. Whitehouse and Hart (1965) used them successfully in nine patients who had suffered gastric intolerance to oral anti-inflammatory drugs; Holt and Hawkins (1965) noted no dyspeptic symptoms in their forty patients, and Woolf (1965) found no evidence of gastric upset in 43 patients. However, Taylor, Huskisson, Whitehouse, and Hart (1969), in a series of patients with gastric ulcers possibly related to indomethacin, noted that three were receiving only suppositories. All had received capsules previously, but in one, an ulcer, which had become smaller after stopping oral indomethacin, enlarged when suppositories were administered. In all three cases, complete radiological healing of the ulcers occurred within a few weeks of stopping suppositories, which suggests that indomethacin can at least delay the healing of such ulcers.

During this trial, the use of $100 \mathrm{mg}$. indomethacin by mouth was not associated with a higher incidence of gastric disturbance, but the trial was too short to draw any definite conclusion from this. A comparison of the long-term effects of the two routes has not been made, but it is our impression that indigestion is a little commoner with the oral route. Boardman and Hart (1967b) found that the development of dyspepsia was not related to dosage. In the series of ten patients with gastric ulcers reported by Taylor and others (1968), four were receiving the orthodox dose of $25 \mathrm{mg}$. three times daily or less.

Systemic side-effects such as headache and dizziness are probably no less common with suppositories and are dose-related. Holt and Hawkins (1965) found them negligible, Whitehouse and Hart (1965) had 
one case, and Woolf (1965) had five. $100 \mathrm{mg}$. indomethacin is not often tolerated during the daytime and there is some suggestion that side-effects may be masked by sleep. Two of our patients found that taking the capsules too early or too late consistently produced headache and dizziness before retiring or on waking next morning.

Anti-inflammatory drugs are particularly useful in relieving the morning pain and stiffness of rheumatoid arthritis. Our current practice, particularly in cases with active disease, is to use $100 \mathrm{mg}$. oral indomethacin at night and up to $75 \mathrm{mg}$. during the day. This regime seems to provide the maximum activity at the appropriate time of day with an acceptable incidence of side-effects in relation to effectiveness. It is often possible to reduce the dose after a few weeks without loss of effect.

\section{Summary}

Oral indomethacin was shown in a double-blind trial to be more effective than the same dose by suppository in relieving the morning symptoms of rheumatoid arthritis. Indomethacin capsules were more slowly absorbed, but 12 hours after administration, there was no difference between the serum levels with the two treatments. About one third of patients developed indigestion during a mean followup of one year, necessitating either withdrawal or reduction of dosage. The use of oral therapy as an alternative to suppositories is discussed.

\section{References}

Boardman, P. L., and HarT, F. Dudley (1967a) Brit. med. J., 4, 264 (Clinical measurement of the anti-inflammatory effects of salicylates in rheumatoid arthritis).

- (1967b) Ann. rheum. Dis., 26, 127 (Side-effects of indomethacin).

Holt, P. J. L., AND Hawkins, C. F. (1965) Brit. med. J., 1, 1354 (Indomethacin: studies of absorption and of the use of indomethacin suppositories).

Mainland, D. (1963) 'Elementary Medical Statistics', 2nd ed., p. 237 Saunders, Philadelphia.

Ropes, M. W., Bennett, G. A., Cobb, S., JACOX, R., AND JesSaR, R. A., (1959) Ann. rheum. Dis., 18, 49 (1958 Revision of diagnostic criteria of rheumatoid arthritis).

Taylor, R. T., Huskisson, E. C., Whitehouse, G. H., Hart, F. Dudley, and Trapnell, D. H. (1968) Brit. med. J., 4, 734 (Gastric ulceration occurring during indomethacin therapy).

Whitehouse, G. H., AND HART, F. Dudley (1965) Ibid., 2, 421, (Indomethacin suppositories for arthritis). WoOLF, D. L., (1965) Ibid., 1, 1497 (Indomethacin suppositories). 